\title{
mLearning, the First Step in the Learning Process Revolution
}

\author{
M.A. Conde ${ }^{1}$, C. Muñoz ${ }^{2}$ and F.J. García ${ }^{1}$ \\ ${ }^{1}$ Universidad de Salamanca, Salamanca, Spain \\ ${ }^{2}$ Clay Formación Internacional, Salamanca, Spain
}

\begin{abstract}
These The learning process is subject to continuous changes due to the changing needs of users. These changes are most often accompanied by new technologies which are constantly appearing in our modern computerized society. The Internet has allowed the optimization of the learning process through supported learning platforms, in addition to this, the dissemination of mobile devices such as P.D.A.'s allows for a new stage in this process, mLearning. This is based on the ability of the user to access their course information at any time and place without the restriction of needing to have a computer in their possession, this along with other characteristics will determine the direction of ubiquitous learning.
\end{abstract}

Index Terms - eLearning, mLearning, uLearning, learning, training, mobile device, learning platform, specification, contents.

\section{INTRODUCTION}

The learning process will be a continuous activity during the lives of all individuals in our society and it must evolve as society itself evolves. Every person should incorporate new knowledge that allows them to adjust to the circumstances they find themselves them in at any given time. The process of obtaining knowledge and learning should be a fundamental part of a person's life.

As time goes by there have taken place and continue to take place great advances in the means of distributing and acquiring knowledge, as well as the means by which these activities are carried out. Nowadays the means to allow the interchange of knowledge, Internet, the TDT and mobile technology are endless. In reality the aim is to allow the user to learn in an effective form at any time or place without relying on outside conditions. With constant technological evolution the time is almost upon us when we can consider it possible to aspire to ubiquitous learning or uLearning. However it is important to temper this possibility with a proviso, although the technology can now allow us to create this opportunity, a pedagogical and technological adjustment will be needed to adapt the contents to a mobile form.

\section{FROM ELEARNING TO ULEARNING}

It is necessary to establish a conceptual base in order understand the transition from eLearning to mLearning and its future evolution to uLearning.

The term eLearning refers to the use of new technologies in the information and communication fields for the purpose of teaching. One of these technologies is the Internet and its contents which have been adapted, but it also includes multimedia technology and simulators. An exhaustive scientific definition of this phenomenon would be "A non face-to-face qualification, which, using technological platforms makes possible the flexible access of knowledge, adapted to the needs and abilities of the learner while also guaranteeing an atmosphere of collaborative learning by means of synchronous and asynchronous communication, harnessing the power by management based on abilities"[5].

It must be taken into account, that, while eLearning is reaching its maturity as a learning method, it must evolve alongside the technology which makes it possible. It is important to consider the importance and acceptance of mobile devices in our society and to consider it as a basis for new models of learning such as mLearning. After studying many definitions of this term the author of this article proposes the following: "mLearning can be understood as an evolution of eLearning which allows students to take advantage of the advantages afforded by mobile technologies to support their learning process and constitutes the first step towards the creation of ubiquitous learning"

Finally uLearning should be mentioned, this would allow the user to access the information at any time, place or situation. A possible definition of uLearning could be the following: "uLearning (ubiquitous learning), a set of formative activities, supported by technology, that are readily accessible in any place [7]”.

To be able to present a historic evolution in the learning process should start from the initial process and should pass afterwards to distance education until the time in which a ubiquitous learning model is created. From the beginning of distance learning in the 1950's, ComputerAided Instruction, which was inacceptable due to computer prices, in the 1960's, through the creation of the Personal Computer and the revolutionary change brought about by new inventions such as CDs and the Internet in the 90's. The next logical step in this process was eLearning which has advanced along with the underlying technology. The evolutions which up until now have taken place and those which will occur in the future are determined by the underlying technological base, this base provides the tools by which the learning process has been improved. Other factors more closely related to mLearning would be the increase in the use of mobile devices and the improvement in their accessibility. It also should be taken into account technologies linked to the Web 2.0, which from a collaborative and universal learning standpoint allow an increase in quality learning leading to uLearning. 


\section{STATE OF ART OF MLEARNING}

Learning through mobile devices involves a new idea of the learning process that will require a series of adaptations, at both a technological and a pedagogical level. It must be taken into consideration that the learning available can depends on factors such as the characteristics of the mobile device being used and the connection available to the terminal. Regarding these two factors and its characteristics, contents and its uses will need an adaptation.

At the pedagogical level there is also the need for several adaptations to adapt to the use of mobile devices. It must be considered the interaction adaptation, learning process adaptation to user location and temporal necessities, content adaptation taking into account the kind of platform the user access to those contents and the adaptation of collaboration process.

Taking into account the types of devices and the adaptation needs there are lot of researches at the moment. Next some of the most common are examined:

Communication tools: The Short Message Service (SMS) which includes mobile phones allows students and professors to contact each other easily and leave messages, seeking consultation regarding doubts, to ask for data or even the results of a task.

Systems with awareness conscience: The possibility of receiving a series of contents based on the situation in which the user finds themselves at any given time. Specifically, ideas such as those proposed by Baeseed [1].

Adaptation System of Content: These allow the different contents that are required in the learning process to be adapted to obtain their maximum benefits from a pedagogical point of view.

Educational games: For decades games have been recognized as a means of advancing and supporting the learning process. In addition to the motivational aspects of these games they can also serve to develop certain abilities and skills such as, reflection, strengthen their understanding of the concepts, strategy and problem solving skills.

Integration of mobile systems in LMS: The inclusion of mobile services in different Learning Management Systems (LMS) is recommended trying to obtain which is known as Mobile Learning Management Systems (mLMS). There are some studies as one of the Athabasca Univesity about how include mobility services in an open source LMS as Moodle [2].

Visualization of standardized learning content: mLearning needs to incorporate content which follows content specifications in order to reuse this contents and which can be viewed clearly through mobile devices. There exist many different specifications for the development and packaging of learning contents. There are several initiatives to do this like Pocket SCORM RunTime Environment (RTE) [6] or some adapted frameworks [4].

\section{PROPOSAL}

In the present section a proposal will be introduced for the introduction of a research thesis. For this research will start from a mobility system proposed by the author in the Group of Research in Interaction and eLearning (GRIAL). This system is based on the learning platform ClayNet 2.0
[3] and is implemented by Alberto Velasco Florines in the University of Salamanca. The aforementioned adaptation process must, as a primary aim, allow the users to access and interact with the learning resources through a mobile device. The aim is to provide a series of web services which the client can easily access. Two main lines of investigation were advanced:

Adaptation and reading of SCORM packages: A definition of this element of adaptation requires a study of the form of representation of the packed contents to determine its visualization means, as well as with Pocket SCORM RTE to determine if it is possible to be used on the present system or if a new adaptation engine is required. A system could be established for the distribution of possible packages adapted by means of web services. It would be adapted to define a system that determines the characteristics of the devices for the adaption process and a pseudo-cache. In order to finish it would be advisable to include a system that allowed for the obtaining of the packages from different repositories and their distribution.

Services for the adaption of LMS to mLMS: As has already been commented it is possible that the platforms of both eLearning and mLearning can co-exist, but the integration of these concepts is not easy and often they will not adapt. What is to be researched in this line is to integrate the previous system of mobile content adaptation to any LMS. Firstly, it is necessary to study the initiatives of structural adaptations already created, such as Mobile Moodle. To redefine the structural system of the present adaptation process including an abstraction layer which allows integration with any platform. This system must include a module to send SMS independently of the LMS used. By establishing this base the existing adaption system should be improved, increasing the types of devices available including PDA's and PALM, introducing new content libraries and subsystems of voice syntheses that allow the adaptation of textual contents.

\section{CONCLUSIONS}

Throughout this article diverse concepts involved in the present learning process have been outlined, they will for the nucleus of this report. It is of utmost importance to allow the individual student to access the knowledge at the time and place of their choosing. Right now is considered the time of the information and technology revolution and both these characteristics will in no way be tangential to the learning process. Over the past years the growth in the use of the Internet and in mobile devices has increased exponentially and this expansion allows us to infer that users want the ability to access more complete and useful services through these devices. eLearning can be considered as one of the greatest steps in the use of new technologies to optimize the learning process. This process has been evolving and will continue to evolve until the demand for services related to mLearning have rendered it obsolete.

Mobile devices have burst onto the scene with almost incomparable speed thanks to price reductions and increase in the number and quality of interactive services. One of these interactive services will be to provide a system of learning to users. The development of this type of system could be considered as the final element in the learning process as it allows information to be accessed 
from devices which can be used at any time or place, however this is not the case. mLearning would be an initial step towards a concept of global learning, in which knowledge is contributed by all society and which could be accessed at any time, place or through any device this concept would be known as uLearning. However there are still many actions to be taken before this situation can be arrived at that is why at first it must be consolidated through mobile devices

There are many possible points which can be improved regarding mobile learning, what we are looking for is to provide more and more complete personalized systems and to satisfy their requirements. It is imperative to focus on the student when working in a global learning environment in which there are so many other actors.

\section{REFERENCES}

[1] Basaeed, E.I. et al 2007. "Web-based Context-Aware m-Learning Architecture”. iJIM. International journal: interactive mobile technologies. Vol 1. No 1, Ed. Papers. Editor Michael E. Auer.

[2] Cheung, B. Stewart, B. McGreal, R. 2006. "Going Mobile with MOODLE: First steps”. Mobile Learning 2006. IADIS.

[3] Conde, M. Á., Carabias, J., Martín, R. Mª González, I., García, F. J. 2006. "Portlet-based ARCHITECTURE FOR A LMS: CLAYNET 2.0". En F. J. García Peñalvo, J. Lozano Galera, F. Lamamie de Clairac Palarea (Eds.).Virtual Campus 2006 Postproceedings. Selected and Extended Papers. CEUR Workshop Proceedings. http://ceur-ws.org/. ISSN 1613-0073. In press.
[4] Drira, R. Tirellil, I. Laroussi, M. Derycke,A.and Benghezala, H. 2006.” What we can adapt in Mobile Learning Systems?”. IMCL 2006. Aman. Jordania.

[5] García, F. J.2006. "Estado Actual de los Sistemas E-Learning.” Teoría de la Educación. Educación y Cultura en la Sociedad de la Información, 6(2). http://www3.usal.es/ teoriaeducacion/rev n umero_06_2/n6_02_art_garcia_penalvo.htm

[6] Lin, N. H., Shih, T. K., Hsu, H.-h., Chang, H.-P., Chang, H.-B., Ko, W. C., et al. 2004. "Pocket SCORM". 24th International Conference on Distributed Computing Systems Workshops - W1: MNSA ICDCSW'04. Taipei, Taiwan.

[7] Ramón, O. 2007. "Del eLearning al uLearning: la liberación del aprendizaje.” Educaterra. http://www.madrimasd.org/tic/Selecc ion/Downloads GetFile.aspx?id=7453.

\section{AUTHORS}

M.A. Conde is with the Departamento de Informática y Automática of the Universidad de Salamanca, Salamanca, Spain.

C. Muñoz is with the Development Department of Clay Formación Internacional, Salamanca, Spain.

F.J. García is with the Departamento de Informática y Automática of the Universidad de Salamanca, Salamanca, Spain.

Manuscript received 31 May 2008. Published as submitted by the authors. 